\title{
Charging Operation Management System of New Energy Vehicle
}

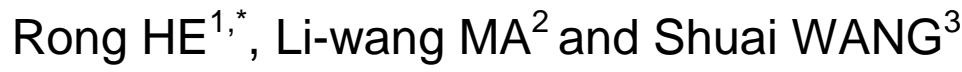 \\ ${ }^{1-3}$ School of Electronic\&Control Engineering Chang'an University Xi'an, \\ 710064, China
}

Keywords: New energy vehicle, COMS, Mobile APP, SQL Server.

\begin{abstract}
According to the fact that new energy vehicle charging facilities is in the promotion stage now with the imperfect operational management and the poor users' experience, a charging operation management system for new energy vehicle is achieved. The system unifies management of charging stations / piles, electric vehicles with Web and $S Q L$ Server database and its data is visible and shareable. Moreover, users can inquiry the information by its APP and GIS technic. The system has the characteristics of TOU price, intelligent charging management, synchronous data display and unattended process. After tested, the system achieves intelligent charging for new energy vehicle, self-service operation on mobile terminal and centralized management for charging equipment which can meet the needs of managers and users.
\end{abstract}

\section{Introduction}

Under the press of the nonrenewable energy resources reduction and global environmental deterioration, as the representative of the new energy vehicles, electric vehicles grows quickly in worldwide sales promoting the development of electric vehicle charging/station simultaneously. However, it is not easy for users to find a nearby chargeable pile when the battery is low. Sometimes, the driver arrives at the charging stations that is broken-down, occupied even no charging pile. So far there are many problems mainly including artificial supervision, lack of scientific charge mechanism and poor reliability of charging equipment. Thus, researching on distributed electric vehicle charging station, intelligent, humanized and automatic charging station operation management platform is developed to improve the basic service quality of electric vehicle charging. That will have great significance for the development and popularization of electric vehicles.

From the view of a manager, the paper [1] constructed a unified information management platform based on WebGIS to adapt to the requirement of mobility and diversity of electric vehicle charging, which was conducive to the unified construction of charging network. The paper [2] made an analysis of the value chain operation mode deeply and excavated the potential of the enterprise to promote the operation and management of new energy charging facilities. The paper [3] introduced two different kinds of structure and operation of charging in the German market.

In this paper, we analyze the characteristics and current states of distributed charging pile operation and management, and combine the intelligent charging equipment and internet of things technology. Meanwhile, from the view of both manager and user, we design an automation system for the electric vehicle charging station using advanced communication technology, data acquisition technology, Web technology, GIS technology and APP Technology. 


\section{System Composition}

The problems of operation management system for new energy vehicle charging mainly consist of two aspects. For managers, centralized monitoring of the charging facilities and electric vehicles are needed to record charging events, fault, consumptions information, etc. For users, they need convenient and quick charging service, scientific visualization of the metering and payment. Consequently, background operation service platform based on internet can realize the management, analysis and dispatch of electric vehicle operation data.

Service operators of electric vehicle take serve as the entrance and provide users with billing and metering, payment accounting, operation management and other services. Actually, centralized monitoring and statistical analysis of the whole charging service process is realized. In addition, based on location and large data analysis of the electric vehicle, users are provided transportation, finance, life and other value-added services. Therefore, on the basis of the existing charging system (only charging car and charging pile), the operation management system and mobile terminal APP are added, which is shown in Fig. 1 for the complete vehicle charging system.

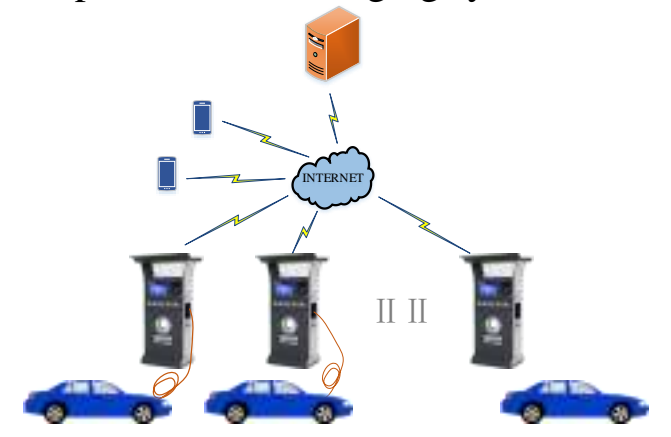

Figure 1. Vehicle charging system components

The management system receives the monitoring data of battery from the station and working state of charging pile, then saves to the system database. Meanwhile, it reserves access interface for management platform and mobile terminal which need to require and invoke web service. Functional design of management system is shown in the Fig. 2. The background server is responsible for the centralized management to electric vehicles, charging piles, charging cards, electric prices, users and other information in detail and accomplish the function of save, inquiry, and modify etc.

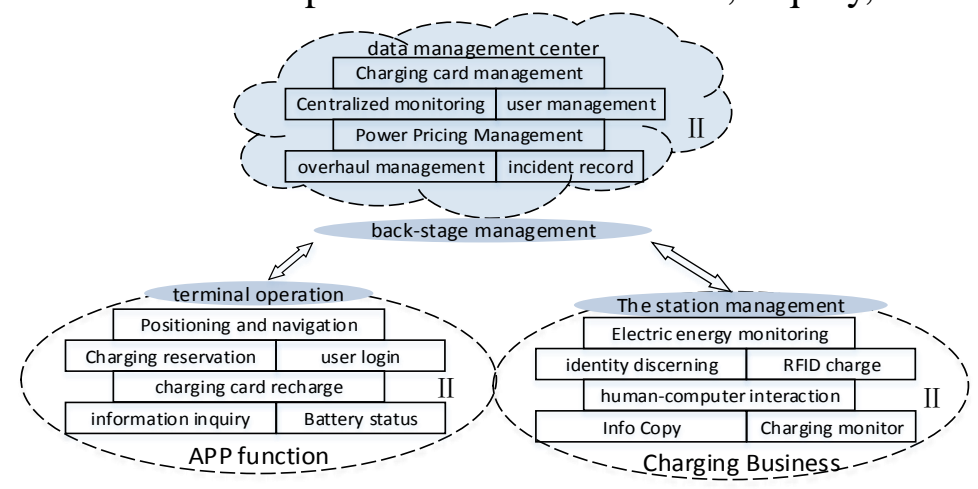

Figure 2. System functions design

Mobile terminal can locate, query the charging pile information in $A P P$, to provide users with reservations and navigation service then, the user can view the state of charging in real-time, and query all charging history, as well as charging card recharge and personal information management. 
As shown in the Fig. 3, the communication between electric vehicle and charging pile adopt $C A N$ bus, and charging pile and management system communicate through internet.

The background service and management platform are developed by the WCF framework based on .NET of Visual Studio 2013. The advantages of WCF include unity, interoperability, security and reliability, high compatibility, so it reaches the requirement of the security, reliability, interoperability, cross platform communication, etc. Besides, SQL Server 2012 data platform is selected to save the information of charging pile position and state, data of charging history, charging cards, price and users. Mobile APP based on Java platform in Eclipse environment enhances the users' experience.

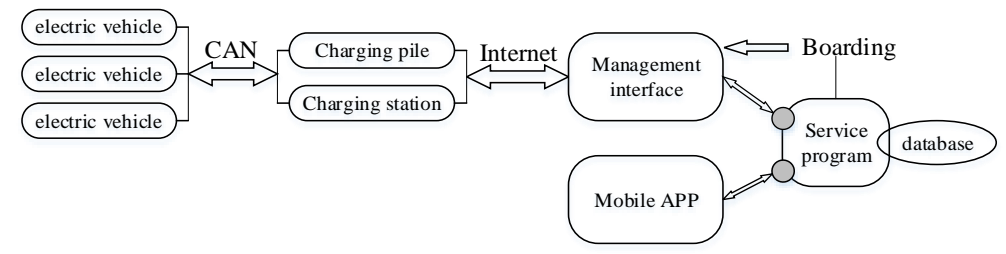

Figure 3. System program framework

\section{Operation Management Interface}

The interface of the system is shown in the Fig.4. Charging pile management, pricing management, charge card management, charging history query, event recording and other functions are listed on the top of the window.

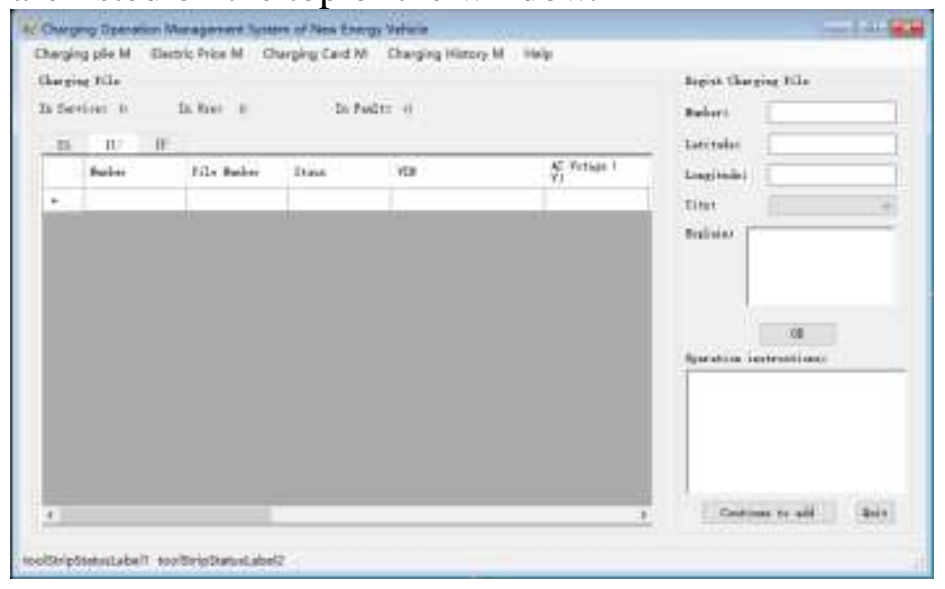

Figure 4. Operation management interface

\section{Charging Pile Management}

Login the management interface can view the information of all the charging pile in service, in use and in fault. The submenu contains register new service charging pile, modify the information of charging piles in service and cancel the out-of-service charging pile.

Firstly, the manager need to input the number, latitude and longitude of Position in order to register a new charging pile. If the number is already exists, it will show the corresponding tips. Secondly, modify the existed pile should enter the number of charging piles to find it, if the pile is not funded, it will gives tips; display all the information after founded. The manager can modify anyone and then just click save. Finally, the cancel the charging pile is similar to modify, confirmation after found. 


\section{Electric Price Management}

The strategy of electricity price is the time of using pricing in the charging operation management system. 24 hours a day is divided into three time periods: peak time(10:00-15:00;18:00-21:00), peacetime(07:00-10:00;15:00-18:00;21:00-23:00), valley time(23:00-morrow07:00). The manager can inquiry and set the electric price of different city. First, pitch on the city and then system will find out the current price, the manager just modify the content and confirm.

\section{Charging Card Management}

In this system, the users' and card information are matched and saved in the database. Management defines the various operations of internal accounts, including registration, recharge, reissue and cancellation.

Users provide name and contact information to the manager and set the password, and then a new card is registered. Inserted the number of the card, system will query the information. Users select the amount they want to charge after confirmation. If the card is lost, the information of old card will be copied to the new card after checked and then be destroyed in the management platform. The administrator only need to enter the user's card number and the system will check the corresponding information automatically, then, click to cancellation after checked.

\section{Events Recording}

The charging history is saved in the database, the administrator can check the history of a charging pile according to its number. In the same way, check the charging history of electric car according to its identification code and check the consumption history of the card according to its card number. Generally speaking, these data can be provided to the government, car and charging pile manufacturers for the next step. Moreover, the recording data include real-time, access and leaving time of car, appointment time of users, down-time of charging pile and so on.

\section{Mobile APP}

In order to improve the experience of electric car users and service quality, mobile terminal APP "To Charge" is developed matching with the operation management system of new energy car charging. "To Charge" is completed based on Java extensible platform, and interface with the background service to transmit JSON data through the HTTP.

The service provided by "To Charge" includes: positioning and navigation, lookup nearby charging piles, charging reservation, charging status monitoring, charging history inquiry, card recharging, personal information management, etc. More specifically, users locate their position and lookup nearby charging pile; Check charging pile working status and position, Select the appropriate charging pile and click to "go there", the $A P P$ will plan an optimal path and navigation.

At the same time, the APP charging booking service will keep for users 30 minutes in order to guarantee charging pile is still available when other users arriving. The service costs 5 Yuan. The system will automatically cancel the reservation if over reservation time.

As shown in Fig. 5, the charging state in real time can be viewed in APP which is a kind of automatic charging without waiting by the side. The charging history and consumption records can be find online. Furthermore, it is the user online feedback 
approach that can get their experience and advice in time to optimize the system. The application of mobile terminal provides users with convenient and efficient service, which guarantee the popularization and application of new energy vehicles.

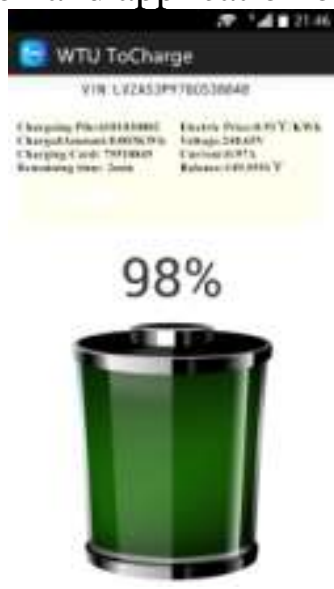

Figure 5. Monitoring of charging

\section{Conclusions}

The operation management system of new energy vehicle charging have intelligentialize the charging, unattended, and human-computer interaction efficiently. Mobile terminal APP provides reservation, navigation, monitoring of charging state service in real-time, which ameliorates the users' experience fundamentally. Ultimately, the intelligent charge really integrate into their lives. Operation management platform has achieved a unified management of online charging, at the same time, the data of charging process, history and fault support for the government, electric vehicles, charging equipment and other manufacturers, which are the construction foundation of smart city.

\section{References}

[1] QF. Liu, Y. Hu, [J]. WebGIS electric power construction, 2014, 01:98-103. "In Chinese"

[2] HW. Feng, [J]. Green building materials, 2016, 02:124-125+119. "In Chinese"

[3] K.M. Winklert, Electric vehicle charging stations in Magdebug[C]. 5th IEEE Vehicle Power and Propulsion Conference, September7-10, 2009, Dearborn, MI, USA: 60-65.

[4] ZY. He, Research on planning method and operation mode of electric vehicle charging station [D]. Beijing Jiaotong University, 2012“In Chinese”

[5] TT. Yin, Design and implementation of charging pile user management system based on IC card [D]. North China Electric Power University (Baoding), 2013“In Chinese"

[6] C.T. BUDDE, C L.WELLS P, [J].Energy Policy, 2012, 48: 498- 505.

[7] LH. Peng, [J]. Web information communication, 2016, (4):10.3969/j.issn.1 673-1131.2016. 04.076. 147-148.DOI: "In Chinese" 
[8] HR. Zhao, Design and research of monitoring and control system for electric vehicle charging station [D]. Zhengzhou: Zhengzhou University, 2011 "In Chinese"

[9] L. Kou, HQ. Hu, [J]. Jiangxi electric power, 2012, 36 (1): 4-6. "In Chinese" 